\title{
The Myostatin gene: an overview of mechanisms of action and its relevance to livestock animals
}

Article

Accepted Version

Aiello, D., Patel, K. and Lasagna, E. (2018) The Myostatin gene: an overview of mechanisms of action and its relevance to livestock animals. Animal Genetics, 49 (6). pp. 505-519. ISSN 1365-2052 doi: https://doi.org/10.1111/age.12696 Available at https://centaur.reading.ac.uk/77388/

It is advisable to refer to the publisher's version if you intend to cite from the work. See Guidance on citing.

To link to this article DOI: http://dx.doi.org/10.1111/age.12696

Publisher: Wiley

All outputs in CentAUR are protected by Intellectual Property Rights law, including copyright law. Copyright and IPR is retained by the creators or other copyright holders. Terms and conditions for use of this material are defined in the End User Agreement.

www.reading.ac.uk/centaur

\section{CentAUR}


Central Archive at the University of Reading

Reading's research outputs online 
1 Review: The Myostatin gene: an overview of mechanisms of action and its

2 relevance to livestock animals

3 D. Aiello ${ }^{1}$, K. Patel ${ }^{2}$ and E. Lasagna ${ }^{1}$

4

$5{ }^{1}$ Dipartimento di Scienze Agrarie, Alimentari e Ambientali, Università degli Studi di

6 Perugia, Borgo XX Giugno 74, 06121, Perugia, Italy

72 School of Biological Sciences, University of Reading, Berkshire, RG6 6UB, United

8 Kingdom

9

10 Corresponding author: Emiliano Lasagna. Fax: +39 075 5857122. Tel: +39 075

11 5857102. E-mail address: emiliano.lasagna@unipg.it

12

13 


\section{Summary}

Myostatin, also known as Growth Differentiation Factor 8, a member of the

17 Transforming Growth Factor-beta (TGF- $\beta$ ) super-family is a negative regulator of muscle development. Myostatin acts at key points during pre- and post-natal life of amniotes which ultimately determine the overall muscle mass of an animal. Mutations have already demonstrated the impact of attenuating Myostatin activity on muscle development. A number of large animals including cattle, sheep, dogs and humans display the 'double muscled' phenotype due to mutations in the Myostatin gene. Here we firstly give an overview of the molecular pathways regulated by Myostatin that control muscle development. Then we describe the natural mutations and their associated phenotypes as well as the physiological influence of altering Myostatin expression in livestock animals (cattle, sheep, goat, horse, pig, rabbit and chicken). Knowledge of null alleles and polymorphisms in the Myostatin gene are of great interest in the animal breeding field and it could be utilized to improve meat production in livestock animals.

Keywords: double muscling, single nucleotide polymorphisms, muscle hypertrophy, muscle hyperplasia, meat production.

\section{Introduction}

Myostatin

Myostatin (MSTN), also known as Growth and Differentiation Factor 8 (GDF8), is one of the major regulators of skeletal muscle development (Beyer et al., 2013). The

MSTN gene (MSTN) is highly conserved among mammalian species and it acts in an 
almost unique manner to reduce muscle size. MSTN-deficient animals display an increase in skeletal muscle mass known as double-muscling (DBM). Mutations in MSTN have been described in numerous species including dog (Mosher et al., 2007), sheep (Kijas et al., 2007), cattle (Grobet et al., 1997), pig (Stinckens et al., 2008) as well as in one human (Schuelke et al., 2004).

Myostatin signalling pathway and its control of skeletal muscle development MSTN is expressed in many tissues (including the mammary gland) but most prominently in skeletal muscle (Ji et al., 1998). The MSTN has been highly conserved throughout evolution and comprises 3 exons and 2 introns.

In all species reported in this review, MSTN exons code for a 375 amino acid latent protein which undergoes significant post-translational modification in order to become biologically active (Wolfman et al., 2003). Firstly, the polypeptide undergoes intracellular homodimerization through the formation of disulphide bonds. Thereafter it is cleaved to form the $\mathrm{N}$-terminal propeptide region and the C-terminal mature region. The 12- KDa C-terminal mature fragment of MSTN initiates an intracellular signalling cascade through its ability to bind and activate the Activin type II receptor at the cell surface (ActRIIB and to a lesser extent ActRIIA). Subsequent autophosphorylation of the ActRIIB leads to the recruitment and activation of low affinity type I receptor for Activin ALK-4 or ALK-5. Activated type I receptor kinase phosphorylates the transcription factors Smad2 and Smad3, allowing them to interact with Smad4 (co-Smad) and translocate to the nucleus, to activate target gene transcription. Importantly the activation of the MSTN receptor also inhibits Akt (protein kinase B) activity, a major determinant in muscle protein synthesis and cell proliferation. Enlargement of muscle fibre size, a process called fibre hypertrophy (or 
simply hypertrophy) is in large part controlled by Akt activity (Trendelenburg et al., 2009). Myogenic differentiation is a highly orchestrated sequential program that ultimately generates mature skeletal muscle. Highly proliferative muscle precursors which arise during embryogenesis differentiate into myoblasts. The commitment of the myogenic lineage is regulated by Muscle Regulatory Factors (MRFs) a collective group of helix-loop-helix transcription factors; namely, MyoD, Myf5, Myogenin and MRF4 (Fig. 1). Additionally, exit from the cell cycle is a vital step during myoblast differentiation (Bryson-Richardson \& Currie, 2008).

MSTN regulates muscle development at key points during the process of pre-natal muscle development: muscle precursor proliferation, myoblast proliferation and differentiation. Studies by Amthor et al. (2002) have shown that ectopic expression (in limb muscle) of MSTN down regulates Pax3; a key marker of proliferating muscle precursors (Amthor et al., 2002). Additionally, MSTN upregulates p21 expression, which ultimately inhibits proliferation of MyoD expressing myoblasts (Thomas et al., 2000). Of relevance to this review is the relationship between MyoD activity and the expression of MSTN. MyoD is an important regulator of MSTN expression during myogenesis. This is demonstrated by a critical role of E-box motifs that were identified in the MSTN promoter region; these motifs are known to be the binding sites for basic helix-loop-helix transcription factors (MRFs) (Hu et al., 2013).

The interrelationship between MyoD and MSTN ensure that promiscuous differentiation mediated by an over-active MyoD induced cascade is checked by the up-regulation of MSTN. Therefore MSTN serves to limit the size of both the myoblast precursor $\left(\mathrm{Pax3}^{+} / \mathrm{MyoD}^{+}\right)$and myoblast $\left(\mathrm{Pax3}^{-} / \mathrm{MyoD}^{+}\right)$pools. Down-regulating the expression of MSTN would lead to an expansion of both populations (Amthor et al., 1999). 
Examination of mouse development shows that muscle mass is determined by the ability of myoblasts to form fibres, a process that occurs in two phases; primary and secondary fibre formation. Matsakas et al. (2010) have shown an increase in the myoblast pool, just before the fibre formation process in Myostatin null mouse (Mstn-1) embryos, which supports the development of extranumerary primary and secondary myofibres. Any programme that promotes an increase in fibre formation is called fibre hyperplasia or simply, hyperplasia (Amthor et al., 2002). Therefore the $\mathrm{Mstn}^{-/}$mouse displays hyperplasia as a consequence of developing an increased number of mononucleated muscle cells (Matsakas et al., 2010).

Shortly before birth, muscle in $\mathrm{Mstn}^{-/}$mice not only contain extra muscle fibres, but also each fibre has undergone a small, albeit significant, increase in size (18\%). However this is not enough to explain why the muscles in this species often weigh 23 times more than their normal counterpart (Omairi et al., 2016). The resolution to this issue comes by examining the size of each muscle fibre in adult mice. This reveals that in the mouse, the increased muscle mass has arisen due to a combination of a pre-natal increase in the number of fibres (hyperplasia) and a precocious post-natal increase (43\%) in the size of each fibre (hypertrophy) (McPherron \& Lee, 1997).

These studies are extremely insightful when attempting to determine the cellular mechanism underpinning double muscling in large mammalian species harbouring a MSTN mutation (Elashry et al., 2012). They predict that for an animal to develop fibre hyperplasia and a small degree of hypertrophy as a consequence of a MSTN mutation, the gene must normally be expressed and properly translated into a mature form during pre-natal development. However, in order to display significant fibre hypertrophy these conditions need to be satisfied during post-natal life. If the mouse 
114 is taken as a guide, then changes in fibre number and small changes in fibre

115 diameter (less than 20\%) can be explained by pre-natal action of MSTN. In cattle, very low levels of MSTN are detected from day 15 to day 29 embryos, and increased expression is detected from day 31 onwards (Kambadur et al., 1997). The increase

118 of MSTN expression in the bovine embryos is thought to occur at a gestational stage

119 when primary myoblasts are starting to fuse and differentiate into myofibres.

120 Therefore the null mutation in the bovine MSTN lead to hyperplasia.

122 Double muscling phenotypes

123 The term hypertrophy has often been used to describe large mammalian species,

124 which display at the gross anatomical level, the enlargement of muscle.

125 Mechanistically this term has been used loosely, since in many cases enlargement of muscle is solely through pre-natal muscle hyperplasia without any post-natal fibre

127 hypertrophy.

128 DBM in large animals has been reported in several species. Generally, muscle with a

129 large superficial area tends to be the most enlarged, while deeper muscles tend to be

130 reduced in size relative to normal muscle (Ouhayon \& Beaumont, 1968). Large

131 commercially important DBM animals, especially cattle, have an excellent

132 conformation and an extremely high carcass yield, coinciding with a reduced internal

133 organ mass (Fiems, 2012).

134 However, these animals are more susceptible to respiratory disease, urolithiasis,

135 lameness, nutritional stress, heat and dystocia resulting in lower robustness (Holmes

136 et al., 1973). Also the reproductive performance can be influenced by hypertrophy:

137 i.e. in the South Devon breed, the gestation period for DBM calves is longer, resulting 138 in offspring with higher birth weights than the normal calves, also evidenced by the 
139 higher instances of dystocia with high mortality rates if births are unassisted; the

140 findings highlighted therefore that the segregating alleles at the MSTN have

141 significant effects on calving ease in this breed (Wiener et al., 2002).

142 DBM cattle showed signs of fatiguing faster than normal cattle during forced

143 exercise; relating to metabolic acidosis, because of a reduced blood circulation

144 leading to a deficiency in the transport of oxygen and a reduction of aerobic

145 metabolic activity in the muscle (Holmes et al., 1973). DBM cattle have in fact an

146 increase in the proportion of fast twitch glycolytic fibres, resulting in a faster and more

147 glycolytic phenotype (Girgenrath et al., 2005).

148 Mutations in the MSTN are responsible for DBM in other large animals including one

149 case in humans. In the latter, Schuelke et al. (2004), observed that a G to A transition

150 at nucleotide gIVS1+5 caused extraordinary muscling in a young boy, especially in

151 the thighs and upper arms. No health problems were reported in the patient and the

152 testosterone and IGF-1 levels were normal. In dogs known as "bully" whippets, a 2-

153 bp deletion was discovered in the third exon of the MSTN is associated with the DBM

154 phenotype. This deletion removes nucleotides 939 and 940 within exon three and

155 leads to a premature stop codon at amino-acid 313 instead of the normal cysteine,

156 removing 63 amino acids from the predicted 375-aa protein (Mosher et al., 2007). A

157 gene targeting approach using the CRISPR/Cas9 system has been used to create

158 MSTN null Beagles; although mutant dogs displayed the DMB phenotype, very little

159 detail is available regarding their cellular phenotype (Zou et al., 2015). Due to the

160 effects of MSTN on muscle mass, growth and other traits, the variations in MSTN

161 expression levels in skeletal muscles are of great interest in the animal breeding

162 field. Knowledge of null alleles and polymorphisms in the MSTN has been utilized to

163 improve the selection of beef cattle and sheep (Georges, 2010). The aim of this 
164 section of the review is to describe known double-muscling in livestock animals that

165 harbour MSTN mutations.

167 Mutations in the Myostatin gene in cattle

168 Monogenic determination of muscular hypertrophy in Belgian Blue cattle was first

169 described in the 1980's (Hanset \& Michaux, 1985; Grobet et al., 1997). Double

170 muscling was shown to be inherited as a single major autosomal locus which

171 nevertheless was affected by several modifier loci manifesting in incomplete

172 penetrance. The causal loss of function mutation in Belgian Blue MSTN, located on

173 chromosome 2, was first reported by Grobet (1997) followed shortly thereafter by the

174 study of McPherron and Lee who not only substantiated the finding of Grobet but

175 also reported a missense mutation in exon 3 in the Piedmontese breed MSTN

176 (McPherron \& Lee, 1997). Approximately 20 different types of genetic variants

177 (deletions, insertions and nucleotide substitutions, also known as single nucleotide

178 polymorphisms - SNPs) have been identified in the bovine MSTN. Some of these

179 genetic variants give rise to muscular hypertrophy by inactivation of the gene (Grobet

180 et al., 1997). Mutated alleles and inactive MSTN have a significant association with

181 growth speed and carcass favourite traits, so these polymorphisms could be used in

182 beef cattle in order to increase the quality and quantity of meat (Mirhoseini \& Zare,

183 2012). In the view of quality meat production, this is an outstanding trait, since these

184 animals produce not just more, but leaner and more tender meat (Kobolák \& Gócza,

185 2002). The carcass and meat quality traits are superior in these animals because of a

186 reduction in fat (decreased by $50 \%$ ), muscle mass increase (by $20 \%$ ) lower

187 proportions of bone and also less connective tissue, which contributes to tenderness

188 (McPherron \& Lee, 1997; Vincenti et al., 2007). However, dystocia-related problems 
189 are often observed in DBM cattle because hyperplasia occurs before birth, resulting

190 in larger calves (Deveaux et al., 2001). Homozygous DBM animals manifest more

191 problems of dystocia than heterozygous. Therefore in order to generate homozygous

192 animals and at the same time keep costs down as well as reducing calve death

193 probability, it is worth considering mating heterozygous animals (Bellinge et al.,

194 2005).

195 A summary of the detected genetic variants in cattle is reported in Table 1.

197 Double muscled cattle breeds

198 Belgian Blue

199 The breed in which this muscular hypertrophy and its effects have been analysed

200 most extensively is the Belgian Blue breed, which has been systematically selected

201 for double muscling to the point of fixation in many herds. Research by Grobet et al.

202 (1997) revealed an 11-bp deletion (nucleotides 821-831) in the open reading frame of

203 the Belgian Blue MSTN allele which results in the loss of 3 amino acids $(275,276$,

204 and 277) and a frameshift after amino acid 274. The frameshift leads to a stop codon

205 after amino acid 287. Work by Wegner et al. (2000) showed that Semitendinosus

206 from Belgian Blue was 1.6 times the weight of normal breeds solely due to an

207 increase in muscle fibre number. Indeed, muscle fibre size from the Belgian Blue was 208 actually smaller than other breeds (Wegner et al., 2000). Furthermore, these animals

209 have less collagen and connective tissue than the normal animals. The carcass fat

210 content in these animals is significantly lower than in normal cattle, especially

211 intramuscular fat (marbling) being influenced by the DBM phenotype with a strong

212 reduction of subcutaneous and internal fat tissues (Mirhoseini \& Zare, 2012). The

213 results of many studies in fact have indicated that MSTN plays key roles in not only 
214 myogenesis but also adipogenesis. MSTN deletion and inhibition in animals mainly

215 lead to increased muscle mass and reduced fat mass (Deng et al., 2017).

216 In beef cattle production, crossing with Belgian Blue cattle shows that although the

217 gene is recessive and monofactorial, its effect is apparent even in heterozygous

218 animals due to its partial dominance (Kobolák \& Gócza, 2002).

219 The same mutation was also found in the Asturiana de los Valles (AV), a Spanish

220 beef cattle breed. MSTN polymorphisms in the AV breed have been described and

221 its diffusion into the breed has been continuous due to economic reasons (Grobet et

222 al., 1997).

224 Piedmontese

225 In Piedmontese cattle the double-muscled phenotype is an inherited condition

226 associated with a $\mathrm{G}$ to $\mathrm{A}$ mutation on nucleotide 938 (in exon 3) which translates to

227 C313Y in a highly conserved cysteine-knot structural motif region of the protein. This

228 is in the pre-helix loop, a region known to be important for ALK $4 / 5$ receptor

229 interaction (Cash et al., 2012). The mutation alters the function of MSTN, which

230 disrupts a disulphide bridge that is essential for the correct conformation of the

231 protein (Kambadur et al., 1997). This breed has been systematically selected for

232 double muscling to the point of fixation in many herds (> 96\% homozygous in the

233 Piedmonte region in Italy), but variability in muscle mass is still present (Miretti et al.,

234 2013). Several studies support the notion that the double muscling phenotype, a

235 partially recessive trait, causes the relatively large effects on carcass conformation,

236 without a negative effect on calving, compared with animals with no copies of the

237 mutated allele (Casas et al., 1998). 
Marchigiana

240 The Marchigiana is one of the most important Italian beef cattle breeds and it is

241 renowned for its large body size, high weight daily gains and superior carcass

242 dressing percent. Marchigiana breed have a $\mathrm{G}$ to $\mathrm{T}$ transversion mutation at

243 nucleotide 874 in exon 3 (g.874G>T), translating to E291X in the MSTN. This point

244 mutation has a remarkable effect on the MSTN as it changes a codon for glutamic

245 acid into a stop codon (Marchitelli et al., 2003). In Marchigiana, as in the other double

246 muscling breeds, the MSTN genotypes yield three different and distinct phenotypes.

247 The homozygous G/G displays the normal phenotype whereas the T/T genotype

248 manifests as a double muscled body shape while maintaining its small frame, and is

249 frequently associated with skeletal defects and serious survival problems due to

250 macroglossia and hypoplasia of the heart, lungs and other vital organs. The

251 heterozygous genotype (G/T) produces a well-muscled and large body structure and

252 excellent conformation without any of the above mentioned defects. Therefore, the

253 heterozygous animals are frequently selected as sires (Cappuccio et al., 1998).

254 Moreover heterozygous animals show a better meat quality than animals with a

255 normal genotype (Vincenti et al., 2007). Therefore they could be useful for breeders

256 to plan the matings to obtain a higher number of heterozygous animals. Obviously

257 this is possible only if the genotype at the MSTN locus of each animal is available.

258 Additionally two different SNPs have been found in the promoter region: g.-371T>A

259 and g.-805G>C, although Sarti et al. (2014) reported that these substitutions may not

260 be useful to be considered in the selection criteria, because there is no correlation

261 with productive traits or due to their homozygous genotype.

263 Other cattle breeds 
An 11 bp deletion (nt821(del11)) resulting in a truncation of the bioactive C-terminal domain of the protein has been found in Blonde d'Aquitaine, Limousine, and Parthenaise and Rubia Gallega breeds (Kambadur et al., 1997; Dunner et al., 2003). A recent study (Bouyer et al., 2014) identified an unexpected mutation in the MSTN in Blonde D'Aquitaine cattle. The mutant allele is highly expressed leading to an abnormal transcript consisting of a 41-bp inclusion between the exons 2 and 3, with a premature termination codon predicted to translate into a protein lacking the entire bioactive region.

An additional transversion mutation $(\mathrm{g} .433 \mathrm{C}>\mathrm{A})$ in Limousine breed has been described that was shown to be functionally associated with the increased muscle mass and carcass yield without any associated reproductive disadvantages (Sellick et al., 2007; Esmailizadeh et al., 2008; Vankan et al., 2010).

As in Piedmontese cattle, a G to A transition at nucleotide position 938 has been reported in Gasconne (Kambadur et al., 1997; Dunner et al., 2003). An insertion/deletion at position 419 replacing $7 \mathrm{bp}$ with an unrelated stretch of $10 \mathrm{bp}$ was reported in Maine-Anjou cattle, resulting in a premature stop codon in the $\mathrm{N}$ terminal latency-associated peptide at amino-acid position 140 (nt419 (del7- ins10)) (McPherron \& Lee, 1997). Additionally, a transversion ( $\mathrm{G}$ to $\mathrm{T}$ ) at nucleotide position 676 , also causing a premature stop codon in the same N-terminal latency-associated peptide at amino-acid position 226 (E226X) was identified in the same breed (Grobet et al., 1997). Charolaise and Limousine have a C to $\mathrm{T}$ transition at nucleotide position 610 yielding a premature stop codon in the $\mathrm{N}$-terminal latency associated peptide at amino-acid positions 204 (Q204X) (Cappuccio et al., 1998). In addition to the genetic variants found in Bos taurus, 14 polymorphisms (three in exon one, seven in exon two, and four in exon three) have been reported in the coding part of the MSTN in 
289 Nellore cattle (Bos indicus) genome. However, whether these polymorphisms are

290 functional mutations still remains to be elucidated (Grisolia et al., 2009).

291

292 Double muscling in sheep

293 The MSTN is located at the end of the long arm (2q32.2 locus) on chromosome 2 in

294 the sheep (Ovis aries) (Bellinge et al., 2005). During the past decade a total of 77

295 MSTN SNPs have been reported in various sheep breeds such as Texel, Norwegian

296 Spælsau, commercial New Zealand sheep breeds and Latvian Darkhead (Kijas et al.,

297 2007, Sjakste et al., 2011; Han et al., 2013), and the majority of these SNPs are

298 located in the non-coding regions of the gene. The exception is a 1-bp deletion

299 identified in nucleotide position 960 in the MSTN of Norwegian White Sheep and

300 c.101G/A in New Zealand Romney, c.120insA (Boman et al., 2009). Lastly in 2018,

301 Trukhachev et al., described for the first time eight variations in non-coding regions of

302 MSTN in the Stavropol Merino, a breed used for meat production in Russia. A

303 summary of the detected genetic variants in sheep is reported in Table 2.

305 Texel

306 Belgian Texel sheep muscle fibres show enlargement and therefore can be

307 considered to have fibre hypertrophy. Texels are utilized extensively as a terminal

308 crossbreed because of their exceptional conformation and potential to produce

309 higher-yielding carcasses with increased lean and decreased fat content (Leymaster

310 \& Jenkins, 1993). Analysing the MSTN revealed no nucleotide differences in the

311 coding regions between DBM and normally muscled breeds (Kijas et al., 2007). This

312 suggests that genetic variation located outside the coding regions plays a more

313 important role in the regulation of muscle development in contrast to cattle, where 
314 MSTN loss of function variants have been found within the three coding exons

315 (Grobet et al., 1997). Quantitative trait locus (QTL) analysis in Texel sheep

316 characterized a mutation (g.6723G $>$ A) in the 3' UTR (Untranslated Region) of the

317 MSTN on chromosome 2 which has an effect on muscle mass. This creates a target

318 site for miR1 and miR206; microRNAs (miRNAs) that are highly expressed in skeletal

319 muscle (Kijas et al., 2007). Other genetic variants have also been found including

320 c. ${ }^{*} 1232 A, g+391 G>T$ and another 18 SNPs: g.2449C>G; g.2379C>T; g.1405A>T;

321 g.1402G>A; g.1214C>T; g.1129C>T; g.41A>C; g.39T>C; g+474C>T; G+613T>C;

$322 \mathrm{~g}+616 \mathrm{G}>\mathrm{A} ; \mathrm{g}+619 \mathrm{~T}>\mathrm{C} ; \mathrm{g}+622 \mathrm{~T}>\mathrm{C} ; \mathrm{g}+632 \mathrm{G}>\mathrm{T} ; \mathrm{g}+696 \mathrm{C}>\mathrm{T} ; \mathrm{g}+3135 \mathrm{C}>\mathrm{T}$;

$323 \mathrm{~g}+4036 \mathrm{~A}>\mathrm{C} ; \mathrm{g}+4044 \mathrm{C}>\mathrm{T}$ (Kijas et al., 2007).

325 Norwegian sheep

326 The DBM phenotype in Norwegian white sheep was described to have extraordinary

327 over-development of the muscles, particularly on the hindquarters. Investigations

328 showed that these animals have not only extremely low levels of subcutaneous fat,

329 but also decreased internal fatty tissues. The DBM animals had lower bone mass

330 compared with the wild type animal. Sequence analysis revealed a 1-bp deletion in

331 the MSTN at nucleotide position 960 in DBM individuals. The deletion of a G residue

332 (c.960delG) disrupted the reading frame from amino acid 320 onwards and produced

333 a premature stop codon at amino acid position 359 (compared to position 375 in the

334 wild type animals) (Boman \& Vage, 2009).

335 The same MSTN 3'-UTR mutation (c.2360G>A) identified in Texel sheep was also

336 found in the Norwegian breed but with a less profound effect (Boman \& Vage, 2009).

337 However a similar phenotype of increased muscle mass and fat was found in

338 Norwegian Spælsau sheep. The sequencing of the MSTN coding region revealed a 
344 New Zealand

345 A comprehensive investigation of polymorphisms in MSTN in a diverse range of

1-bp insertion at nucleotide position 120 (c.120insA) in DBM animals. The insertion of an adenine residue disrupts the reading frame from amino acid position 40 onwards, and generates a premature stop codon at amino-acid position 49 (Boman \& Vage, 2009). sheep breeds (New Zealand Romney, Coopworth, Corriedale, Dorper, Perendale, Suffolk, Merino, Dorset Down, Poll Dorset, Texel and other NZ cross-bred sheep) was performed using polymerase chain reaction-single strand conformational polymorphism (PCR-SSCP) analysis and DNA sequencing. A total of 28 nucleotide substitutions were identified from nucleotide c.-1199 (in the promoter region) to c. ${ }^{*} 1813$ in the 3 'UTR. Of these, three were located in the promoter region, three in the 5'UTR, 11 in intron 1, five in intron 2 and five in the 3' UTR. Ten new substitutions have been reported: c. $-959 \mathrm{C}>\mathrm{T}$, c. $-784 A>\mathrm{G}$, c. $373+563 A>\mathrm{G}$, c. $373+607 A>\mathrm{G}$, c.374654G $>A$, c. $374-54 T>C$, c. $748-54 T>C, c .{ }^{*} 83 A>G, c .{ }^{*} 455 A>G$ and c. ${ }^{*} 709 C>A(H a n$ et al., 2013).

The other 18 substitutions had been reported previously. These include c.101G>A which was already found in NZ Romney by Zhou et al. (2008) and also in Merino, Corriedale and NZ cross-bred sheep (Clop et al., 2006; Kijas et al., 2007). In NZ Romney a further two SNPs c.-2449G/C and c.-2379T/C were detected (Wang et al., 2016). The SNP c. ${ }^{*} 123 A$ observed in NZ cross-bred sheep was also reported in Texel (Kijas et al., 2007), Charollais sheep from Britain (Hadjipavlou et al., 2008), White Suffolk, Poll Dorset and Lincoln breeds from Australia and showed significant 
association with DBM phenotype as well as the other substitution c. $373+18 \mathrm{~T}>\mathrm{G}$, reported in Texel sheep (Clop et al., 2006).

\section{Other sheep breeds}

Zel sheep, a meat breed in northern Iran, has a polymorphism in intron 2 as does the Iranian Baluchi sheep (Dehnavi et al., 2012). Three polymorphic sites in Indian sheep have been identified in the 5'UTR, exon 1 and exon 2 regions. Both SNPs in the exonic region were found to be non-synonymous. The genetic variants c.539T>G and c.821T>A were in the exon 1 and exon 2, respectively (Pothuraju et al., 2015). All these genetics variants are not significantly associated with DBM phenotype.

\section{Myostatin polymorphisms in goat}

Several studies investigated the allelic variation in the goat MSTN. A 5 bp indel (1256 TTTTA/-) was identified in 5'UTR region in Boer, Matou, Haimen and Nubi goat breeds, and a substitution (1388 T/A) in exon 1 region was detected only in Boer (Zhang et al., 2012). Two novel single nucleotide polymorphisms were also identified in Boer and Anhui white goat: g.197G>A, a substitution located in the 5'-UTR, and 345A $>\mathrm{T}$ in the exon 1 (Zhang et al., 2013). A thorough investigation was conducted in 22 different goat breeds (Inner Mongolia Cashmere, Liaoning Cashmere, Taihang Mountain, Chengde Polled, Jining Grey, Tibetan, Chengdu Brown, Jianchang Black, Guizhou White, Guizhou Black, Longlin, Duan goat, Leizhou, Matou, Yichang White, Shannan White, Nanjiang Brown, Angora, Toggenburg, Nubian, Saanen and Boer goat) and a total of eight SNPs were detected (A1980G, G1981C, A1982G, G1984T, A2121G, T2124C, G2174A and A2246G) (Li et al., 2006). Recently Nguluma et al. (2018) detected a polymorphic site T298C in the Boer goat population: the authors 
concluded that the potential association of this polymorphism in MSTN with growth performance could not be confirmed and that other genes for growth could be responsible for the observed variation. A summary of the detected genetic variants in goat is reported in Table 3.

\section{Myostatin polymorphisms in horse}

Hosoyama et al. (2002) isolated and sequenced MSTN cDNA from a Thoroughbred horse which was mapped to chromosome 18. Mutations in the equine MSTN have been identified and are associated with racing phenotypes influencing racing performance and muscle fibre proportions (Petersen et al., 2013). Dall'Olio et al. (2010) sequenced in 16 horse breeds (Rapid Heavy Draft, Noric, Bardigiano, Haflinger, Lipizzan, Murgese, Tolfetano, Uruguayan Creole, Italian Saddle, Maremmano, Quarter Horse, Salernitano, Andalusian, Ventasso, Italian trotter, Thoroughbred horse) revealing seven SNPs: two transitions were located in the promoter region at -646 (GQ183900: g.26T>C) and -156 (GQ183900: g.156T>C) bp upstream from the start codon and are associated with breeds of different morphological types. The g.26T>C SNP was polymorphic in 6/16 breeds with higher observed frequency of the g.26C allele. The g.156T>C polymorphism was detected in 11/16 breeds and was identified in homozygous condition in a few Bardigiano, Haflinger, Noric, Rapid Heavy Draft, and Uruguayan Creole horses (Dall'Olio et al., 2010). The other five SNPs were in intronic regions: four were localized in intron 1 and one in intron 2. Three of the SNPs of intron 1 (g.1634T>G, g.2115A $>\mathrm{G}$, and g.2327A >C) were also identified in Thoroughbred breeds (Petersen et al., 2013). One polymorphism (g.2115A $>\mathrm{G}$ ) has been associated with sprinting ability and racing stamina in Thoroughbred horses. The association between MSTN and horse racing 
413 performances was further evidenced by Binns et al. (2010) and Tozaki et al. (2010).

414 Subsequently 15 Chinese breeds were studied to select the best Chinese domestic 415 breed to evaluate the potential racing performances (Li et al., 2014). These studies 416 found six different SNPs in MSTN: two SNPs (g.26T>C and g.156T >C) in the 417 promoter region, two ( $.587 \mathrm{~A}>\mathrm{G}$ and $\mathrm{g} .598 \mathrm{C}>\mathrm{T})$ in the 5 '-UTR region, and two 418 (g.1485C > T, g.2115A $>\mathrm{G}$ ) in intron-1 of the equine MSTN, respectively. The SNPs g.587A $>\mathrm{G}$ and g.598C $>$ T were novel whereas the others had been previously 420 reported (Petersen et al., 2013).

421 Baron et al. (2012) described a genetic variant in exon 2 in some horse breeds. In 422 fact, they identified a substitution g.2279A $>C$ in Arabians horses and a substitution 423 g.2478G $>C$ in the Soraia breed horse.

424 Five polymorphisms (g.66495826T >C, g.66495696T>C, g.66493737T>C, g.66495254C>T and g.66490010T>C) were recently observed (Stefaniuk et al., 2016) in four Polish breeds (Arabians, Polish Konik, Hucul and Polish Heavy Draft). The polymorphism g.66495254C>T (also known as g.598C >T), has been described 428 in Chinese horse breeds as well as in Polish Konik and Arabian horse breeds. The 429 g.66493737C > T polymorphism known to predict optimum distance in Thoroughbred 430 horses has been identified in four breeds in Egyptian bloodlines (Bower et al., 2012) 431 which were introduced to Polish bloodstock through Egyptian stallions. The insertion g.66495326_66495327Ins227 has been described for the first time in MSTN in

433 Thoroughbred horses. Recently, it has been found in the American Quarter Horse 434 (Petersen et al., 2013), and in the Uruguayan Creole breeds (Dall'Olio et al., 2014). 435 In the Quarter Horse breed, the Ins227 in MSTN is connected with changes to 436 Gluteus medius muscle fibre proportions. The higher Myosin Heavy Chain 2B fibre 437 type (fast contracting), is in line with pressure selection in Quarter Horse breed for 
438 racing performance (Petersen et al., 2013). A summary of the detected genetic

439 variants in horse is reported in Table 4.

441 Myostatin polymorphisms in pig

442 Jiang et al. (2002) reported three SNPs in porcine MSTN T>A, G>A and C>T, in the

443 promoter, intron 1 and exon 3, respectively. Only one mutation ( $T$ to $A$ ) located in the

444 region 383bp upstream of translation initiation site of porcine MSTN was associated

445 with average daily gain in the growing period (from 60 to $100 \mathrm{~kg}$ of live weight) in

446 Yorkshire pigs. Furthermore BW in pig with the heterozygous mutation (no AA was

447 found) was increased (Jiang et al., 2002).

448 Stinckens et al. (2008) compared the MSTN sequence of Belgian Piétrain, which

449 shows a heavily muscled phenotype with five other breeds (Piétrain, Landrace, Large

450 White, Meishan and Wild Boar). Fifteen polymorphic loci were found, three of which

451 were located in the promoter region (g.435G $>A, g .447 A>G$, and g.879T $>A$ ), five in

452 intron 1 and seven in intron 2. The SNP g.879T>A only appears in Chinese Meishan

453 pigs whilst the polymorphism located at position 447 of the porcine MSTN promoter

454 had a very high allele frequency in the Piétrain pig breed. A g.447A > G mutation

455 which is associated with the expression of the porcine MSTN occurs at the putative

456 myocyte enhancer factor 3 (MEF3) binding site on the negative DNA strand. This

457 mutation disrupts a putative MEF3 binding site (Stinckens et al., 2008).

458 However, these results suggest that naturally occurring MSTN genetic variants

459 identified thus far in pigs do not have significant association with muscle phenotypes.

460 Nevertheless, a recent work, using an experimental approach has shown the role of

461 MSTN in the development of muscle in pigs. Qian et al. (2015) generated MSTN-

462 deficient Meishan pigs using zinc finger nucleases (ZFN) technology coupled with 
463

464

465

466

467

468

469

470

471

472

473

474

475

476

477

478

479

480

481

482

483

484

485

486

487

somatic cell nucleus transfer. The resulting offspring show remarkable DBM

phenotype especially pronounced in the hindquarters. Muscle in the MSTN null pig

increased mass by $50-100 \%$. Incredibly the muscle fibre size in the null pigs was

smaller than the wild type. All the increase in mass could be attributed to fibre

hyperplasia whereby some muscles from the null had twice the fibre number

compared to wild type. The animals displayed good overall health. As the technology

employed did not involve the introduction of any genetic material in to the genome

(e.g. selection markers), Qian et al. (2015) suggest that it is essentially the same as

double muscle cattle which are used for human consumption.

A summary of the detected genetic variants in pigs is reported in Table 5 .

Myostatin polymorphisms in rabbit

Fontanesi et al. (2011) investigated the variability of the effects of MSTN

polymorphisms on rabbit production traits. Four single SNPs have been identified by comparative sequencing of 14 rabbits representing breeds or lines having different conformation and muscle mass: one rare synonymous SNP in exon 1 (c.108C>T), one synonymous SNP in exon 2 (c.713T>A), one SNP in the 3'-untranslated region (c. $\left.{ }^{*} 194 A>G\right)$ and another SNP in intron $2(c .747+34 C>T)$ in Belgian hare, Burgundy fawn, Checkered giant and Giant grey.

In commercial hybrids, Qiao et al. (2014) detected a SNP (T to C) in the 5' regulatory region, but no mutation sites were detected in the exons. The correlation analysis showed that the mutation was associated with increased liver and carcass weight. These results suggest that the mutations in the upstream regulatory region of the MSTN are beneficial to the rabbit soma development, and the mutations can be used as molecular markers for the selection of the meat quality in rabbits. Sternstein et al. 
488 (2014) found polymorphisms in the MSTN in Giant Grey and NZ White breeds.

489 Comparative sequencing of these breeds revealed two SNPs located in the

490 regulatory region of the rabbit $\operatorname{MSTN}(\mathrm{c} .-125 \mathrm{~T}>\mathrm{C})$ and in intron 1 (c.373+234T>C).

491 A summary of the detected genetic variants in rabbit is reported in Table 6.

493 Myostatin polymorphisms in poultry

494 In chickens MSTN maps to 7p11 (Sazanov et al., 1999), and like that of mammals is 495 composed of three exons (373 bp, 374 bp and 1567 bp, respectively) and two 496 introns. Gu et al. (2003) showed poultry MSTN not only regulates skeletal muscle 497 development, but also participates in the fat metabolism and disposition. This 498 research team identified seven SNPs: five were in the 5'-regulatory region (G167A, 499 T177C, G304A, A322G, and C334T) and two were in the 3'-regulatory region of 500 different chicken lines. These last two SNPs in the 3'-regulatory region of the MSTN 501 are A to T (7263) and A to G (6935). Ye et al. (2007) studied the association of MSTN 502 polymorphism with mortality rate, growth, feed conversion efficiency, ultrasound 503 breast depth, breast percentage, eviscerated carcass weight, leg defects, blood 504 oxygen level, and hen antibody titer to the infectious bursal disease virus in three 505 commercial broiler chicken lines. The MSTN had pleiotropic effects on broiler performance. This conclusion was reached by the discovery of fourteen SNPs: seven 507 genetic variants in exon 1 (G2100A, G2109A, G2244C, A2283G, C2346T, C2373T, 508 A2416G), one in exon 2 (T4842G), three in exon 3 (C7434G, A7435G, C7436A), and 509 three in intron 1 and 2 (A4405C, A4405T and A4954G).

510 As the main function of MSTN is the regulation of skeletal muscle growth, Ye et al. 511 (2007) deemed that the non-synonymous SNP T4842G is associated with an amino 512 acid change in the MSTN and it could be responsible for variability in body weight. 
513 The Bian chicken breed raised for dual purposes, is an important Chinese breed and

514 has a 234G>A in exon 1 of the MSTN (Zhang et al., 2012). Other Chinese chicken

515 breeds (Jinghai, Youxi, and Arbor Acre) have shown four new mutations (A326G,

516 C334G, C1346T, G1375A) that were located in the 5'-regulatory region (Zhang et al.,

517 2012). Further studies on the growth traits show that the SNPs in chicken MSTN may

518 affect the abdominal fat weight and percentage, breast muscle weigh and

519 percentage, birth weight, and adult weight (Zhang et al. 2012). Zhiliang et al. (2004)

520 identified three SNPs in the 5' regulatory region and two SNPs in the 3' regulatory

521 region, and these differed in allele frequencies between breeds. They found that in

522 an F2 generation from a cross of broiler and silky chickens, homozygous genotypes

$523 A A$ and $B B$ at a locus in the 5 ' regulatory region have a higher abdominal fat weight

524 and abdominal fat percentage than $A B$ genotype (Zhiliang et al., 2004). The

525 upstream promoter region of MSTN was analysed in Wenshang Luhua chicken DNA.

526 Thirteen E-boxes were identified upstream of MSTN and the polymorphisms of E-

527 boxes were explored for the first time (Hu et al., 2013).

528 Other interesting studies were carried out on ducks to investigate the association of

529 polymorphisms in MSTN with slaughter traits, breast muscle weight, breast muscle

530 percentage, leg muscle weight and leg muscle percentage. Analysis of the $5^{\prime}$

531 regulatory region of the MSTN showed that polymorphisms $(753 \mathrm{G}>\mathrm{A}, 658 \mathrm{G}>\mathrm{T}$ and

$532235 \mathrm{G}>\mathrm{C}$ ) were associated with the breast muscle percentage and abdominal fat rate

533 (Lu et al., 2011). Furthermore Xu et al. (2013) studied polymorphisms in Pekin duck,

534 and identified three significant variations. The first is a transition $\mathrm{T}$ to $\mathrm{C}$ in the ORF

535 (position 129) and revealed an association with breast muscle thickness. The second

536 SNP was located at $708 \mathrm{bp}$ for the $\mathrm{T} / \mathrm{C}$ mutation in the ORF and last $952 \mathrm{~T}<\mathrm{C}$ had a

537 significant association with the "Fossilia Ossis Mastodi, or dragon bone" length. In 
538 Gaoyou ducks, a transition $\mathrm{G}>\mathrm{A}$ at $2701 \mathrm{bp}$ in exon 3 of the MSTN is correlated with 539 the abdominal fat rate (Liu et al., 2012). In Sansui duck, six SNPs were identified in

540 the first and the third exons (g.106G $>A, g .120 A>G, g .159 G>A, g .5368 G>A$,

541 g.5389A >C and g.5410G >A) with four loci seemingly associated to leg muscle

542 weight, leg muscle percentage and dressing percentage (Zhao et al., 2016).

543 A summary of the detected genetic variants in poultry is reported in Table 7.

545 Myostatin and future implications

546 According to some investigators, MSTN mutations are the main cause of

547 hypertrophy, with a lesser roles played by other gene mutations (Kobolák \& Gócza, 548 2002). Inactivation of MSTN has therefore been proposed to be a strategy for

549 improving muscle growth of food animals and treating human diseases associated 550 with muscle weakness and dystrophy (Chen \& Lee, 2016).

551 Research, especially on mice, has highlighted the potential of manipulating MSTN 552 signalling in order to promote muscle growth. In null mutants of this species, some 553 muscles are approximately three times their normal weight. Impressive as they are, 554 muscle enlargement in large mammals carrying a null mutation in the same gene, to 555 our knowledge, do not approach this level of muscle growth. Therefore it is important 556 to ascertain the molecular basis underpinning these different responses with a view 557 of translating these findings into increased meat production.

558 One picture that emerges through this review is that mutations that compromise

559 MSTN function have a consequence during development and give rise to 560 supernumerary muscle fibres (hyperplasia). However, one of the clear differences 561 between mice and large animals (cattle and pigs) is the post-natal phenotype. Mice

562 show considerable fibre hypertrophy whereas in both cattle and pigs display no 
563 increase in fibre size. These findings need to be used as a benchmark for future work

564 on doubling muscle in large animals. First and foremost is the need to understand the

565 basis of muscle growth in large mammals. Here it is very important to use the correct

566 terms to describe the phenotype of animals, as often this can lead to

567 misinterpretations regarding mechanism. Often DBM animals are referred to as being

568 'Hypertrophic'. However this could infer fibre enlargement. As we have discussed, 569 especially in the case of cattle and pig, there is no fibre enlargement. We suggest

570 that accurate mechanistic descriptors are used when they have been precisely

571 established and without this proof a more generic term needs to be applied. We

572 suggest the use of the four following terms: 1) Muscle enlargement through

573 hyperplasia; 2) Muscle enlargement through hypertrophy; 3) Muscle enlargement

574 through hyperplasia and hypertrophy; 4) Muscle enlargement through unknown 575 cellular mechanisms.

576 Research is required to understand the mechanisms that underpin the role of MSTN

577 in post-natal muscle development in mammals, to answer the question as to why in

578 the absence of MSTN, fibres from mice undergo enlargement, whereas those from

579 large mammals do not. For a number of years the naturally occurring mutants in

580 cattle were our only reference model for large animals lacking MSTN. The lack of

581 fibre hypertrophy was usually explained by the presence of a secondary (to date

582 unidentified) modifying mutation that interfered with the post-natal effect but sparred

583 the pre-natal phenotype. However the work by Qian et al. (2015) in the pig which

584 targets only the MSTN undermines the modifying gene idea. Therefore loss of

585 function mutation in both small and large animals leads to hyperplasia. However it is

586 only in mice that the mutation has an effect on muscle fibre size where it presents as

587 hypertrophy. 
588 Clues to resolving this issue come from recent work in monkeys which shows that MSTN and Activin act synergistically to inhibit fibre hypertrophy during adult life

590 (Latres et al., 2017). Based on these findings we suggest that muscle fibres of both cows and pigs are sensitive to Myostatin/Activin signalling, in a similar manner to monkeys. But the issue that still needs to be resolved is why do fibres in adult cows and pigs fail to enlarge in the absence of MSTN. The most parsimonious explanation

594 is that there is a partial redundancy relationship between MSTN and Activin; in the absence of MSTN, the expression levels of Activin become elevated to such a degree that in cows and pigs the latter can completely cover the loss of the former.

597 Examples of gene expression compensation by related molecules, similar to our 598 proposal are abound in mammalian biology (Barbaric et al., 2007). One of the best 599 examples comes through the investigations of MRFs where genetic inactivation of 600 MyoD results in an up-regulation of the related gene-Myf5 (Rudnicki et al., 1992).

601 The hypothesis outlined above has a number of important implications. Our assertion 602 of why the relationship between MSTN and Activin in cows and pigs is only partial 603 and not complete, come from the fact that loss of MSTN has some phenotypic 604 consequence (hyperplasia). Therefore compensation through an up-regulation of 605 Activin expression cannot have occurred during pre-natal life. The second implication 606 is that if there is a redundancy mechanism in mice, which must be very muted since 607 these animals develop a profound phenotype both during pre-natal and adult life. Our 608 suggestions can be validated by quantifying the levels of MSTN and Activin at 609 different developmental stages in both large and small animals, an avenue now 610 possible following the development of specific ELISA for MSTN and Activin (Latres et 611 al., 2017). 
612 For the meat industry and for the human health sector who focus on muscle growth,

613 the hypothesis outlined here advocates a strategy of dual MSTN and Activin

614 antagonism to promote the growth of the tissue. This could be achieved through the

615 use of a combination of molecules that specifically antagonise the activity of MSTN

616 and Activin (antibodies or protein specific propeptides) or a single protein which acts

617 at a signalling convergence point (at the receptor level through the deployment of a

618 ligand trap or blocking antibody (Omairi et al., 2016, Lach-Trifilieff et al., 2014).

619 Moreover for beef production it will be very interesting to better understand the role of

620 MSTN in adipogenesis; Deng et al. (2017) in fact reported that muscle and adipose

621 tissue develop from the same mesenchymal stem cells, and researchers have found

622 that MSTN is expressed in fat tissues and plays a key role in adipogenesis.

623 Finally MSTN is a prime target for transgenic approaches aimed at enhancing meat

624 production in livestock (Georges, 2010). Possible strategies for this outcome include

625 the generation of MSTN knock-out animals. Also more elaborate transgenic

626 approaches, such as targeting post-natal or sex specific inhibition of MSTN need to

627 be considered. Wang et al. (2017), reported the successful application of the

628 CRISPR/Cas9 system to engineer the goat genome through micro-injection of Cas9

629 mRNA and sgRNAs targeting MSTN in goat embryos. They demonstrate the utility of

630 this approach by disrupting MSTN, resulting in enhanced body weight and larger

631 muscle fiber size in Cas9-mediated gene modified goats. MSTN activity can also be

632 modified using non-genetic approaches using for example blocking antibodies or

633 ligand traps.

634

\section{Conclusions}

636 One picture that emerges through this review is that mutations that compromise 
637 MSTN function have a consequence during development and give rise to

638 supernumerary muscle fibres (hyperplasia). However, one of the clear differences

639 between mice and large animals (cattle and pigs) is the post-natal phenotype. First

640 and foremost there is the need to understand the basis of muscle growth in large

641 mammals.

642 This review landscapes the genetics of DBM in mammalian species and chicken and

643 demonstrates the huge number of genetic variants present in animals of commercial

644 interest. It also highlights areas where greater research is required in order for

645 progress to be made concerning the role of MSTN in the regulation of muscle

646 development in economically important animals. Knowledge of null alleles and

647 polymorphisms in MSTN are of great interest in the animal breeding field and could

648 be utilized to improve the selection for meat production in livestock animals.

649

650 Conflict of interest

651 The authors have no conflict of interest to declare.

652

\section{Acknowledgements}

654 The authors want to thank the three anonymous referees for their valuable comments 655 and constructive suggestions.

656

657 References

658 Amthor H., Christ B. \& Patel K. (1999) Molecular mechanism enabling continuous

659 embryonic muscle growth - a balance between proliferation and differentiation.

660 Development 126, 1041-53. 
661 Amthor H., Huang R., McKinnell I., Christ B., Kambadur R., Sharma M. \& Patel K.

662 (2002) The regulation \& action of myostatin as a negative regulator of muscle

663 development during avian embryogenesis. Developmental Biology 251, 241-57.

664 Barbaric I., Miller G. \& Dear T.N. (2007) Appearances can be deceiving: phenotypes 665 of knockout mice. Briefings in Functional Genomics 6, 91-103.

666 Baron E.E., Lopes M.S., Mendonça D. \& Da Câmara Machado A. (2012) SNP 667 identification and polymorphism analysis in exon 2 of the horse myostatin gene. 668 Animal Genetics 43, 229-32.

669 Bellinge R.H., Liberles D.A., laschi S.P., O'Brien P.A. \& Tay G.K. (2005) Myostatin \& 670 its implications on animal breeding: a review. Animal Genetics 36, 1-6.

671 Beyer T.A., Narimatsu M., Weiss A., David L. \& Wrana J.L. (2013) The TGF $\beta$ 672 superfamily in stem cell biology and early mammalian embryonic development.

673 Biochimica et Biophysica Acta 1830, 2268-79.

674 Binns M.M., Boehler D.A. \& Lambert D.H. (2010) Identification of the myostatin locus 675 (MSTN) as having a major effect on optimum racing distance in the Thoroughbred 676 horse in the USA. Animal Genetics 41, 154-8.

677 Boman I.A., Klemetsdal G., Blichfeldt T., Nafstad O. \& Våge D.I. (2009) A frameshift 678 mutation in the coding region of the myostatin gene (MSTM) affects carcass 679 conformation and fatness in Norwegian White Sheep (Ovis aries). Animal Genetics, $68040,418-22$.

681 Boman I.A. \& Våge D.I. (2009) An insertion in the coding region of the myostatin 682 (MSTN) gene affects carcass conformation and fatness in the Norwegian Spaelsau 683 (Ovis aries). BMC Research Notes 2, 98. 
684 Bouyer C., Forestier L., Renand G. \& Oulmouden A. (2014) Deep intronic mutation 685 and pseudo exon activation as a novel muscular hypertrophy modifier in cattle. Public Library of Science One 9, 97399.

687 Bower M.A., Mcgivney B.A., Campana M.G., Gu J., Andersson L.S., Barrett E., Davis 688 C.R., Mikko S., Stock F., Voronkova V., Bradley D.G., Fahey A.G., Lindgren G., 689 Machugh D.E., Sulimova G. \& Hill E.W. (2012) The genetic origin and history of 690 speed in the Thoroughbred racehorse. Nature Communications 3, 643.

691 Bryson-Richardson R.J. \& Currie P.D. (2008) The genetics of vertebrate myogenesis.

692 Nature Reviews Genetics 9, 632-46.

693 Cappuccio I., Marchitelli C. \& Serracchioli A. (1998) A G T transversion induces a 694 stop codon at the mh locus in hypertrophic Marchigiana beef subjects. Animal 695 Genetics 29, 51.

696 Casas E., Keele J.W., Shackelford S.D., Koohmaraie M., Sonstegard T.S., Smith 697 T.P., Kappes S.M. \& Stone R.T. (1998) Association of the muscle hypertrophy locus 698 with carcass traits in beef cattle. Journal of Animal Science 76, 468-73.

699 Cash J.N., Angerman E.B., Kattamuri C., Nolan K., Zhao H., Sidis Y., Keutmann H.T. 700 \& Thompson T.B. (2012) Structure of myostatin-follistatin-like 3: N-terminal domains 701 of follistatin-type molecules exhibit alternate modes of binding. Journal of Biological 702 Chemistry 287, 1043-53.

703 Chen P.R. \& Lee K. (2016) Invited review: inhibitors of myostatin as methods of 704 enhancing muscle growth and development. Journal of animal science, 94, 3125-34.

705 Clop A., Marcq F., Takeda H., Pirottin D., Tordoir X., Biber B., Bouix J., Caiment F., 706 Elsen J.M., Eychenne F., Larzul C., Laville E., Meish F., Milenkovic D., Tobin J., 707 Charlier C. \& Georges M. (2006) A mutation creating a potential illegitimate 
708 microRNA target site in the myostatin gene affects muscularity in sheep. Nature

709 Genetics 38, 813-8.

710 Dall'Olio S., Fontanesi L., Nanni Costa L., Tassinari M., Minieri L. \& Falaschini A.

711 (2010) Analysis of horse myostatin gene and identification of single nucleotide

712 polymorphisms in breeds of different morphological types. Journal of Biomedicine

713 and Biotechnology 542945.

714 Dall'Olio S., Wang Y., Sartori C., Fontanesi L. \& Mantovani R. (2014) Association of

715 myostatin (MSTN) gene polymorphisms with morphological traits in the Italian Heavy

716 Draft Horse breed. Livestock Science 160, 29-36.

717 Dehnavi E., Ahani Azari M., Hasani S., Nassiry M.R., Mohajer M., Khan Ahmadi A.,

718 Shahmohamadi L. \& Yousefi S. (2012) Polymorphism of Myostatin gene in intron 1

719 and 2 and exon 3, and their associations with yearling weight, using PCR-RFLP and

720 PCR-SSCP Techniques in Zel Sheep. Biotechnology Research International,

721472307.

722 Deng B., Zhang F., Wen J., Ye S., Wang L., Yang Y., Gong P. \& Jiang, S. (2017) The

723 function of myostatin in the regulation of fat mass in mammals. Nutrition \&

724 metabolism 14, 29.

725 Deveaux V., Cassar-Malek I. \& Picard B. (2001) Comparison of contractile

726 characteristics of muscle from Holstein and double-muscled Belgian Blue foetuses.

727 Comparative biochemistry and physiology. Part A, Molecular and integrative

728 physiology 131, 21-9.

729 Dunner S., Miranda M.E., Amigues Y., Cañón J., Georges M., Hanset R., Williams J.

730 \& Ménissier F. (2003) Haplotype diversity of the myostatin gene among beef cattle

731 breeds. Genetics Selection Evolution 35, 103-18. 
732 Elashry M.I., Collins-Hooper H., Vaiyapuri S. \& Patel K. (2012) Characterisation of

733 connective tissue from the hypertrophic skeletal muscle of myostatin null mice.

734 Journal of Anatomy 220, 603-11.

735 Esmailizadeh A.K., Bottema C.D., Sellick G.S., Verbyla A.P., Morris C.A., Cullen N.G.

736 \& Pitchford W.S. (2008) Effects of the myostatin F94L substitution on beef traits.

737 Journal of Animal Science 86, 1038-46.

738 Fiems L.O. (2012) Double Muscling in Cattle: Genes, Husbandry, Carcasses and

739 Meat. Animals 2, 472-506.

740 Fontanesi L., Scotti E., Frabetti A., Fornasini D., Picconi A. \& Russo V. (2011)

741 Identification of polymorphisms in the rabbit (Oryctolagus cuniculus) myostatin

742 (MSTN) gene and association analysis with finishing weight in a commercial rabbit

743 population. Animal Genetics 42, 339.

744 Georges M. (2010) When less means more: impact of myostatin in animal breeding.

745 Immunology, Endocrine \& Metabolic Agents in Medicinal Chemistry 10, 240-248.

746 Girgenrath S., Song K. \& Whittemore L.A. (2005) Loss of myostatin expression alters

747 fiber-type distribution and expression of myosin heavy chain isoforms in slow- and

748 fast-type skeletal muscle. Muscle Nerve 31, 34-40.

749 Grisolia A.B., D’Angelo G.T., Porto Neto L.R., Siqueira F. \& Garcia J.F. (2009)

750 Myostatin (GDF8) single nucleotide polymorphisms in Nellore cattle. Genetics and

751 Molecular Research 8, 822-30.

752 Grobet L., Martin L.J., Poncelet D., Pirottin D., Brouwers B., Riquet J., Schoeberlein

753 A., Dunner S., Ménissier F., Massabanda J., Fries R., Hanset R. \& Georges M.

754 (1997) A deletion in the bovine myostatin gene causes the double-muscled

755 phenotype in cattle. Natural Genetics 17, 71-4. 
756 Gu Z.L., Zhu D.H., Li N., Li H., Deng X.M. \& Wu C.X. (2003) Polymorphisms of

myostatin gene and its relationship with the development of skeletal muscle and fat in chickens. Science China Life Sciences 33, 273-80.

Hadjipavlou G., Matika O., Clop A. \& Bishop S.C. (2008) Two single nucleotide polymorphisms in the myostatin (GDF8) gene have significant association with muscle depth of commercial Charollais sheep. Animal Genetics 39, 346-53.

Han J., Forrest R.H. \& Hickford J.G. (2013) Genetic variations in the myostatin gene (MSTN) in New Zealand sheep breeds. Molecular Biology Reports 40, 6379-84.

Hanset R. \& Michaux C. (1985) On the genetic determinism of muscular hypertrophy in the Belgian White and Blue cattle breed. I. Experimental data. Genetics Selection Evolution 17, 359-68.

Holmes J.H., Ashmore C.R. \& Robinson D.W. (1973) Effects of stress on cattle with hereditary muscular hypertrophy. Journal of Animal Science 36, 684-94.

Hosoyama T., Kawada S., Oshiumi R., Yoneda S., Soeta C., Yamanouchi K., Hasegawa T., Ishida N., Mukoyama H., Ishii N. \& Tachi C. (2002) Molecular cloning of equine (thoroughbred) myostatin cDNA and detection of myostatin precursor proteins in the serum. Journal of Reproduction and Development 48, 335-42. Hu W., Chen S., Zhang R. \& Lin Y (2013) Single nucleotide polymorphisms in the upstream regulatory region alter the expression of myostatin. In Vitro Cellular and Developmental Biology 49, 417-23.

Ji S., Losinski R.L., Cornelius S.G., Frank G.R., Willis G.M., Gerrard D.E., Depreux F.F. \& Spurlock M.E. (1998) Myostatin expression in porcine tissues: tissue specificity and developmental and postnatal regulation. American Physiological Society $\mathbf{2 7 5}, \mathbf{1 2 6 5 - 7 3 .}$ 
780 Jiang Y.L., Li N., Plastow G., Liu Z.L., Hu X.X. \& Wu C.X. (2002) Identification of

781 three SNPs in the porcine myostatin gene (MSTN). Animal Biotechnology 13, 173-

782178.

783 Kambadur R., Sharma M., Smith T.P. \& Bass J.J. (1997) Mutations in myostatin

784 (GDF8) in double-muscled Belgian Blue and Piedmontese cattle. Genome Research

$7857,910-16$.

786 Kijas J.W., McCulloch R., Edwards J.E., Oddy V.H., Lee S.H. \& Van Der Werf J.

787 (2007) Evidence for multiple alleles effecting muscling and fatness at the ovine GDF8

788 locus. BioMedCentral Genetics 8, 80.

789 Kobolák J. \& Gócza E. (2002) The role of the myostatin protein in meat quality-a

790 review. Archives Animal Breeding, 45, 159-70.

791 Lach-Trifilieff E., Minetti G.C., Sheppard K., Ibebunjo C., Feige J.N., Hartmann S.,

792 Brachat S., Rivet H., Koelbing C., Morvan F., Hatakeyama S. \& Glass D.J. (2014) An

793 antibody blocking activin type II receptors induces strong skeletal muscle hypertrophy

794 and protects from atrophy. Molecular Cell Biology 34, 606-18.

795 Langley B., Thomas M., Bishop A., Sharma M., Gilmour S. \& Kambadur R. (2002)

796 Myostatin inhibits myoblast differentiation by down-regulating MyoD expression.

797 Journal of Biological Chemistry 277, 49831-40.

798 Latres E., Mastaitis J., Fury W., Miloscio L., Trejos J., Pangilinan J., Okamoto H.,

799 Cavino K., Na E., Papatheodorou A., Willer T., Bai Y., Hae Kim J., Rafique A.,

800 Jaspers S., Stitt T., Murphy A.J., Yancopoulos G.D., Gromada J. (2017) Activin A

801 more prominently regulates muscle mass in primates than does GDF8. Nature

802 Communications 8,15153. 
Leymaster K.A. \& Jenkins T.G. (1993) Comparison of Texel- and Suffolk-sired

804 crossbred lambs for survival, growth, and compositional traits. Journal of Animal

805 Science 71, 859-69.

806 Li X.L., Wu Zh L., Gong Y.F., Liu Y.Q., Liu Z.Z., Wang X.J., Xin T.R. \& Ji Q. (2006)

807 Single-nucleotide polymorphism identification in the caprine myostatin gene. Journal 808 of Animal Breeding and Genetics 123,141-4.

809 Li R., Liu D.H., Cao C.N., Wang S.Q., Dang R.H., Lan X.Y., Chen H., Zhang T., Liu

810 W.J. \& Lei C.Z. (2014) Single nucleotide polymorphisms of myostatin gene in

811 Chinese domestic horses. Gene 538, 150-4.

812 Liu Q., Chen Y.H., Cai F.X., Zhu W.Q., Wang Z.Y. \& Zhang T.J. (2012)

813 Polymorphisms in exon 3 of MSTN gene and its relationship with abdominal fat rate 814 in Gaoyou duck. China Poultry 34, 24-30.

815 Lu J., Hou S., Huang W., Yu J. \& Wang W. (2011) Polymorphisms in the myostatin 816 gene and their association with growth and carcass traits in duck. African Journal of 817 Biotechnology 54, 11309-12.

818 Marchitelli C., Savarese M.C., Crisà A., Nardone A., Marsan P.A. \& Valentini A.

819 (2003) Double muscling in Marchigiana beef breed is caused by a stop codon in the 820 third exon of myostatin gene. Mammalian Genome 14, 392-5.

821 Matsakas A., Otto A., Elashry M.I., Brown S.C. \& Patel K. (2010) Altered primary and 822 secondary myogenesis in the myostatin-null mouse. Rejuvenation Research 13, 717$823 \quad 27$.

824 McPherron A.C. \& Lee S.J. (1997) Double muscling in cattle due to mutations in the 825 myostatin gene. Proceedings of the National Academy of Sciences USA 94, 12457$826 \quad 61$. 
827 Mirhoseini S.Z. \& Zare J. (2012) The role of myostatin on growth and carcass traits

828 and its application in animal breeding. Life Science Journal, 9, 2353-57.

829 Miretti S., Martignani E., Accornero P. \& Baratta M. (2013) Functional effect of mir-

$83027 \mathrm{~b}$ on myostatin expression: a relationship in Piedmontese cattle with double-

831 muscled phenotype. BioMedCentral Genomics 14, 194.

832 Mosher D.S., Quignon P., Bustamante C.D., Sutter N.B., Mellersh C.S., Parker H.G.

833 \& Ostrander E.A. (2007) A mutation in the myostatin gene increases muscle mass

834 and enhances racing performance in heterozygote dogs. Public Library of Science

835 Genetics 3, 79.

836 Nguluma A.S., Huang Y., Zhao Y., Chen L., Msalya G., Lyimo C., Guangxin E. \&

837 Chenyambuga S.W. (2018) Polymorphisms of Myostatin gene and its association

838 with growth in two strains of Small East African and Blended goats of Tanzania.

839 Livestock Research for Rural Development 30, 25.

840 Omairi S., Matsakas A., Degens H., Kretz O., Hansson K.A., Solbrå A.V., Bruusgaard

841 J.C., Joch B., Sartori R., Giallourou N., Mitchell R., Collins-Hooper H., Foster K.,

842 Pasternack A., Ritvos O., Sandri M., Narkar V., Swann J.R., Huber T.B. \& Patel K.

843 (2016) Enhanced exercise and regenerative capacity in a mouse model that violates

844 size constraints of oxidative muscle fibres. Elife 5.

845 Ouhayon J. \& Beaumont A. (1968) Etude du charactere culard: study of the double-

846 muscled character III microscopical comparison of muscles from normal and double-

847 muscled Charolais steers. Annales De Zootechnie 17, 213-23.

848 Petersen J.L., Mickelson J.R., Rendahl A.K., Valberg S.J., Andersson L.S., Axelsson

849 J., Bailey E., Bannasch D., Binns M.M., Borges A.S., Brama P., Da Câmara

850 Machado A., Capomaccio S., Cappelli K., Cothran E.G., Distl O., Fox-Clipsham L.,

851 Graves K.T., Guérin G., Haase B., Hasegawa T., Hemmann K., Hill E.W., Leeb T., 
852 Lindgren G., Lohi H., Lopes M.S., McGivney B.A., Mikko S., Orr N., Penedo M.C.,

853 Piercy R.J., Raekallio M., Rieder S., Røed K.H., Swinburne J., Tozaki T., Vaudin M.,

854 Wade C.M. \& McCue M.E. (2013) Genome-wide analysis reveals selection for

855 important traits in domestic horse breeds. Public Library of Science Genetic 9,

856 e1003211.

857 Pothuraju M., Mishra S.K., Kumar S.N., Mohamed N.F., Kataria R.S., Yadav D.K. \&

858 Arora R. (2015) Polymorphism in the coding region sequence of GDF8 gene in Indian 859 sheep. Genetika 51, 1297-300.

860 Qian L., Tang M., Yang J., Wang Q., Cai C., Jiang S., Li H., Jiang K., Gao P., Ma D.,

861 Chen Y., An X., Li K. \& Cui W. (2015) Targeted mutations in myostatin by zinc-finger

862 nucleases result in double-muscled phenotype in Meishan pigs. Scientific Reports 5,

86314435.

864 Qiao X.B., Xu K.Y., Li B., Luan X., Xia T. \& Fan X.Z. (2014) Rabbit MSTN gene

865 polymorphisms and genetic effect analysis. Genetics and Molecular Research 13, $866 \quad 2590-97$.

867 Rudnicki M.A., Braun T., Hinuma S. \& Jaenisch R. (1992) Inactivation of MyoD in

868 mice leads to up-regulation of the myogenic HLH gene Myf-5 and results in

869 apparently normal muscle development. Cell 71, 383-90.

870 Sarti F.M., Lasagna E., Ceccobelli S., Di Lorenzo P., Filippini F., Sbarra F., Giontella

871 A., Pieramati C. \& Panella F. (2014) Influence of single nucleotide polymorphisms in

872 the myostatin and myogenic factor 5 muscle growth-related genes on the

873 performance traits of Marchigiana beef cattle. Journal of Animal Science 92, 3804-

87410.

875 Sazanov A., Ewald D., Buitkamp J. \& Fries R. (1999) A molecular marker for the

876 chicken myostatin gene (GDF8) maps to 7p11. Animal Genetics 30, 388-9. 
877 Schuelke M., Wagner K.R., Stolz L.E., Huibner C., Riebel T., Kömen W., Braun T., 878 Tobin J.F. \& Lee S.J. (2004) Myostatin mutation associated with gross muscle 879 hypertrophy in a child. New England Journal of Medicine 350, 2682-8.

880 Sellick G.S., Pitchford W.S., Morris C.A., Cullen N.G., Crawford A.M., Raadsma H.W. 881 \& Bottema C.D. (2007) Effect of myostatin F94L on carcass yield in cattle. Animal 882 Genetics 38, 440-6.

883 Sjakste T., Paramonova N., Grislis Z., Trapina I. \& Kairisa D. (2011) Analysis of the 884 single-nucleotide polymorphism in the 5, D. I d part of intron 1 of the sheep MSTN 885 gene. DNA and Cell Biology 30, 433.

886 Stefaniuk M., Kaczor U. \& Kulisa M. (2014) MSTN gene polymorphism in livestock 887 animals. Postępy Higieny i Medycyny Doświadczalnej 68, 633-9.

888 Stefaniuk M., Ropka-Molik K., Piórkowska K., Kulisa M. \& Podstawski Z. (2016) 889 Analysis of polymorphisms in the equine MSTN gene in Polish populations of horse 890 breeds. Livestock Science 187, 151-7.

891 Sternstein I., Reissmann M., Maj D., Bieniek J. \& Brockmann G.A. (2014) A new 892 single nucleotide polymorphism in the rabbit (Oryctolagus cuniculus) myostatin 893 (MSTN) gene is associated with carcass composition traits. Animal Genetics 45, 5968949.

895 Stinckens A., Luyten T., Bijttebier J., Van Den Maagdenberg K., Dieltiens D., 896 Janssens S., De Smet S., Georges M. \& Buys N. (2008) Characterization of the 897 complete porcine MSTN gene and expression levels in pig breeds differing in 898 muscularity. Animal Genetics 39, 586-96.

899 Thomas M., Langley B., Berry C., Sharma M., Kirk S., Bass J. \& Kambadur R. (2000) 900 Myostatin, a negative regulator of muscle growth, functions by inhibiting myoblast 901 proliferation. Journal of Biological Chemistry 275, 40235-43. 
902 Tozaki T., Miyake T., Kakoi H., Gawahara H., Sugita S., Hase-Gawa T., Ishida N., 903 Hirota K. \& Nakano Y. (2010) A genome-wide association study for racing 904 performances in Thoroughbreds clarifies a candidate region near the MSTN gene. 905 Animal Genetics 41, 28-35.

906 Trendelenburg A.U., Meyer A., Rohner D., Boyle J., Hatakeyama S. \& Glass D.J. 907 (2009) Myostatin reduces Akt/TORC1/p70S6K signaling, inhibiting myoblast 908 differentiation and myotube size. American Journal of Physiology-Cell Physiology 909 296, 1258-70.

910 Trukhachev V., Yatsyk O., Telegina E., Krivoruchko A., Zhou H. \& Hickford J.G.H. 911 (2018) Comparison of the myostatin (MSTN) gene in Russian Stavropol Merino 912 sheep and New Zeland Merino sheep. Small Ruminant Research, 160, 103-6.

913 Vankan D.M., Waine D.R. \& Fortes M.R. (2010) Real-time PCR genotyping and 914 frequency of the myostatin F94L mutation in beef cattle breeds. Animal 4, 530-4.

915 Vincenti F., Failla S., Gigli S., Lasagna E., Landi V., Mangione A., Berti C. \& Sarti 916 F.M. (2007) The Hypertrophic Marchigiana: physical and biochemical parameters for 917 meat quality evaluation. Italian Journal of Animal Science 6, 491-3.

918 Wang J., Zhou H., Hu J., Li S., Luo Y. \& Hickford J.G.H. (2016) Two single nucleotide 919 polymorphisms in the promoter of the ovine myostatin gene (MSTN) and their effect 920 on growth and carcass muscle traits in New Zealand Romney sheep. Journal of 921 Animal Breeding and Genetics 133, 219-26.

922 Wang X., Niu Y., Zhou J., Zhu H., Ma B., Yu H., Yan H., Hua J., Huang X., Qu L. \& 923 Chen Y. (2017) CRISPR/Cas9-mediated MSTN disruption and heritable mutagenesis 924 in goats causes increased body mass. Animal Genetics 49, 43-51. 
925 Wegner J., Albrecht E., Fiedler I., Teuscher F., Papstein H.J. \& Ender K. (2000)

926 Growth- and breed-related changes of muscle fiber characteristics in cattle. Journal

927 of Animal Science 78, 1485-96.

928 Wiener P., Smith J.A., Lewis A.M., Woolliams J.A. \& Williams J.L. (2002) Muscle-

929 related traits in cattle: the role of the myostatin gene in the South Devon breed.

930 Genetics Selection Evolution 34, 221-32.

931 Wolfman N.M., McPherron A.C., Pappano W.N., Davies M.V., Song K., Tomkinson

932 K.N., Wright J.F., Zhao L., Sebald S.M., Greenspan D.S. \& Lee S.J. (2003) Activation

933 of latent myostatin by the BMP-1/tolloid family of metalloproteinases. Proceedings of

934 the National Academy of Sciences USA 100, 15842-46.

935 Xu T.S., Gu L.H., Zhang X.H., Ye B.G., Liu X.L. \& Hou S.S. (2013) Characterization

936 of myostatin gene (MSTN) of Pekin duck and the association of its polymorphism

937 with breast muscle traits. Genetics and Molecular Research 12, 3166-77.

938 Ye X.H., Brown S.R., Nones K., Coutinho L.L., Dekkers J.C.M. \& Lamont S.J. (2007)

939 Associations of myostatin gene polymorphisms with performance and mortality traits

940 in broiler chickens. Genetics Selection Evolution 39, 73-89.

941 Zhang C., Liu Y., Xu D., Wen Q., Li X., Zhang W. and Yang L. (2012) Polymorphisms

942 of myostatin gene (MSTN) in four goat breeds and their effects on Boer goat growth

943 performance. Molecular Biology Reports 39, 3081-7.

944 Zhang G., Zhang L., Wei Y., Wang J., Ding F., Dai G. \& Xie K. (2012) Polymorphisms

945 of the myostatin gene and its relationship with reproduction traits in the Bian chicken.

946 Animal Biotechnology 23, 184-93.

947 Zhang Z.J., Ling Y.H., Wang L.J., Hang Y.F., Guo X.F., Zhang Y.H., Ding J.P. \&

948 Zhang X.R. (2013) Polymorphisms of the myostatin gene (MSTN) and its relationship

949 with growth traits in goat breeds. Genetics and Molecular Research 12, 965-71. 
950 Zhao Z., Li H., Yi H. \& Peng B. (2016) The correlation between polymorphisms of the 951 MSTN gene and slaughter traits in sansui ducks. Pakistan Journal of Zoology 48, $952 \quad 1283-90$.

953 Zhiliang G., Dahai Z., Ning L., Hui L., Xuemei D. and Changxin W. (2004) The single 954 nucleotide polymorphisms of the chicken myostatin gene are associated with skeletal 955 muscle and adipose growth. Science China Life Sciences 47, 25-30.

956 Zhou H., Hickford J.G.H. \& Fang Q. (2008) Variation in the coding region of the 957 myostatin (GDF8) gene in sheep. Molecular and Cellular Probes 22, 67-8.

958 Zou Q., Wang X., Liu Y., Ouyang Z., Long H., Wei S., Xin J., Zhao B., Lai S., Shen 959 J., Ni Q., Yang H., Zhong H., Li L., Hu M., Zhang Q., Zhou Z., He J., Yan Q., Fan N., 960 Zhao Y., Liu Z., Guo L., Huang J., Zhang G., Ying J., Lai L. \& Gao X. (2015)

961 Generation of gene-target dogs using CRISPR/Cas9 system. Journal of Molecular 962 Cell Biology 7, 580-3. 


\section{LEGENDS TO FIGURES}

965 Figure 1 Myostatin action during myoblast proliferation and differentiation (modified 966 from Langley et al., 2002). Retinoblastoma protein (Rb), in a low phosphorylated

967 state, inhibits cell division. Rb activity is attenuated due to hyper-phosphorylation by 968 the kinase action of CKD2. However the activity of CDK2 is inhibited by p21 which is 969 induced by the action of MSTN. MSTN also activates Smad2/3 signalling which 970 inhibits the expression of $M y o D$ which is needed for normal myoblast differentiation.

971 In the absence of MSTN, the activity of CDK2 is not inhibited which allows it to

972 inactivate $\mathrm{Rb}$ resulting in increased proliferation of myoblasts. At the same time the 973 expression of $M y O D$ is no longer inhibited by Smad2/3 signalling pathways allowing it 974 to promote differentiation of the extranumerary myoblasts.

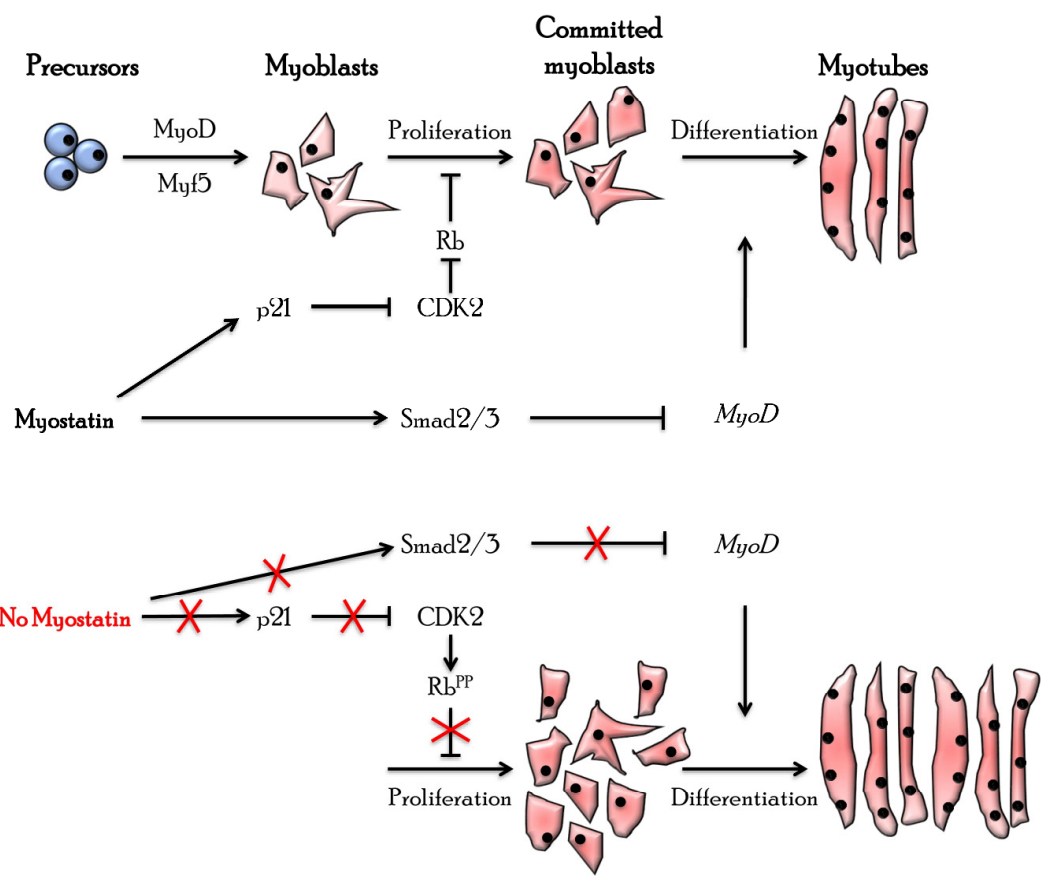


977 Table 1 Polymorphisms on Myostatin gene in cattle.

\begin{tabular}{|c|c|c|c|}
\hline \multirow{2}{*}{ Breed } & \multicolumn{2}{|c|}{$\begin{array}{l}\text { Polymorphisms } \\
\text { on MSTN }\end{array}$} & \multirow{2}{*}{ Reference } \\
\hline & position & mutation & \\
\hline $\begin{array}{c}\text { Asturiana de los } \\
\text { Valles } \\
\end{array}$ & nt821 & DEL11 & Grobet et al., $199 \overline{982}$ \\
\hline Belgian Blue & nt821 & DEL11 & McPherron \& Lee, 1927 \\
\hline $\begin{array}{c}\text { Blonde } \\
\text { d'Aquitaine }\end{array}$ & $\begin{array}{c}\mathrm{nt821} \\
\mathrm{nt} 3811 \\
\end{array}$ & $\begin{array}{c}\text { DEL11 } \\
\text { T>G }\end{array}$ & $\begin{array}{r}\text { Kambadur et al., } 19998 \\
\text { Bouyer et al., } 201486\end{array}$ \\
\hline Charolaise & nt610 & $\mathrm{C}>\mathrm{T}$ & Kambadur et al., 19888 \\
\hline Gasconne & nt938 & $\mathrm{G}>\mathrm{A}$ & $\begin{array}{r}\text { Kambadur et al., } 19999 \\
\text { Dunner et al., 20030 }\end{array}$ \\
\hline Limousine & $\begin{array}{l}\mathrm{nt} 821 \\
\mathrm{nt610} \\
\text { g.433 } \\
\end{array}$ & $\begin{array}{c}\text { DEL11 } \\
\text { C>T } \\
\text { C }>A\end{array}$ & $\begin{array}{l}\text { Kambadur et al., } 19993 \\
\text { Cappuccio et al., } 19989 \\
\text { Sellick et al., 200894 }\end{array}$ \\
\hline Maine-Anjou & $\begin{array}{l}\mathrm{nt} 419 \\
\mathrm{nt676} \\
\end{array}$ & $\begin{array}{c}\text { del-7-ins10 } \\
\text { G>T }\end{array}$ & $\begin{array}{l}\text { McPherron \& Lee, } 19997 \\
\text { Grobet et al., 199696 }\end{array}$ \\
\hline Marchigiana & g.874 & $\mathrm{G}>\mathrm{T}$ & Cappuccio et al., 19998 \\
\hline Nellore & $\begin{array}{c}\mathrm{nt76} \\
\mathrm{nt111} \\
\mathrm{nt267} \\
\mathrm{nt374} \\
\mathrm{nt414} \\
\mathrm{nt420} \\
\mathrm{nt} 433 \\
\mathrm{nt445} \\
\mathrm{nt527} \\
\mathrm{nt641} \\
\mathrm{nt694} \\
\mathrm{nt840} \\
\mathrm{nt951} \\
\mathrm{nt1083} \\
\end{array}$ & $\begin{array}{c}A>T \\
G>T \\
A>G \\
D E L 16 \\
C>T \\
T>G \\
A>T \\
A>T \\
T>A \\
G>A \\
G>A \\
A>G \\
T>G \\
C>T \\
\end{array}$ & Grisolia et al., 2009 \\
\hline Parthenoise & nt821 & DEL11 & Kambadur et al., 1997 \\
\hline Piedmontese & nt938 & $\mathrm{G}>\mathrm{A}$ & Kambadur et al., 1997 \\
\hline Rubia Gallega & nt821 & DEL11 & Kambadur et al., 1997 \\
\hline
\end{tabular}


Table 2 Polymorphisms on Myostatin gene in sheep.

\begin{tabular}{|c|c|c|c|}
\hline \multirow{2}{*}{ Breed } & \multicolumn{2}{|c|}{$\begin{array}{l}\text { Polymorphisms } \\
\text { on MSTN }\end{array}$} & \multirow{2}{*}{ Reference } \\
\hline & position & mutation & \\
\hline Texel & $\begin{array}{c}g .6723 \\
g+391 \\
g .2449 \\
g .2379 \\
g .1405 \\
g .1402 \\
g .1214 \\
g .1129 \\
g .41 \\
g .39 \\
g+474 \\
G+613 \\
g+616 \\
g+619 \\
g+622 \\
g+632 \\
g+696 \\
g+3135 \\
g+4036 \\
g+4044\end{array}$ & $\begin{array}{l}G>A \\
G>T \\
C>G \\
C>T \\
A>T \\
G>A \\
C>T \\
C>T \\
A>C \\
T>C \\
C>T \\
T>C \\
G>A \\
T>C \\
T>C \\
G>T \\
C>T \\
C>T \\
A>C \\
C>T\end{array}$ & Kijas et al., 2007 \\
\hline $\begin{array}{c}\text { Norwegian White } \\
\text { Sheep }\end{array}$ & $\begin{array}{l}\text { c. } 960 \\
\text { c. } 2360\end{array}$ & $\begin{array}{l}\mathrm{DEL1} \\
\mathrm{G}>\mathrm{A}\end{array}$ & Wang et al., 2016 \\
\hline $\begin{array}{l}\text { New Zealand } \\
\text { Romney }\end{array}$ & $\begin{array}{c}\text { c. } 101 \\
\text { c. }-959 \\
\text { c. }-784 \\
\text { c. } 373+18 \\
\text { c. } 373+563 \\
\text { c. } 373+607 \\
\text { c. } 374-654 \\
\text { c. } 374-54 \\
\text { c. } 748-54 \\
\text { c. }{ }^{*} 83 \\
\text { c. } 455 \\
\text { c. }{ }^{*} 709 \\
\text { c. }{ }^{*} 123 A \\
\text { c. }-2449 \\
\text { c. }-2379 \\
\end{array}$ & $\begin{array}{l}G>A \\
C>T \\
A>G \\
A>G \\
A>G \\
G>A \\
T>C \\
T>C \\
A>G \\
A>G \\
C>A \\
I N S A \\
T>G \\
G>C \\
T>C \\
T\end{array}$ & $\begin{array}{l}\text { Wang et al., } 2016 \\
\text { Kijas et al., } 2007\end{array}$ \\
\hline Charollais & c. ${ }^{*} 123 \mathrm{~A}$ & & Kijas et al., 2007 \\
\hline White Suffolk & c. ${ }^{*} 123 \mathrm{~A}$ & & Kijas et al., 2007 \\
\hline Poll Dorset & c. ${ }^{*} 123 \mathrm{~A}$ & & Kijas et al., 2007 \\
\hline Lincoln & c. ${ }^{*} 123 \mathrm{~A}$ & & Kijas et al., 2007 \\
\hline
\end{tabular}




\begin{tabular}{|c|c|c|c|}
\hline Indian sheep & $\begin{array}{l}c .539 \\
c .821\end{array}$ & $\begin{array}{l}T>G \\
T>A\end{array}$ & Pothuraju et al., 2015 \\
\hline Stavropol Merino & $\begin{array}{c}\text { c. } 373+396 \\
\text { c. } 374-362 \\
\text { c. } 374-16 \\
\text { c. } 747+185 \\
\text { c. } 748-194 \\
\text { c. } 782 \_783 \\
\text { c. } 940 \\
\text { c. }{ }^{*} 310\end{array}$ & $\begin{array}{c}T>C \\
A>T \\
D E L T \\
C>A \\
C>A \\
I N S T \\
G>T \\
G>T\end{array}$ & Trukhachev et al., 2018 \\
\hline
\end{tabular}

1001

1002 
1003 Table 3 Polymorphisms on Myostatin gene in goat.

\begin{tabular}{|c|c|c|c|}
\hline \multirow[t]{2}{*}{ Breed } & \multicolumn{2}{|c|}{$\begin{array}{l}\text { Polymorphisms } \\
\text { on MSTN }\end{array}$} & \multirow[t]{2}{*}{ Reference } \\
\hline & position & mutation & \\
\hline Anhui white & $\begin{array}{l}\text { g.197 } \\
\text { nt345 }\end{array}$ & $\begin{array}{l}G>A \\
A>T\end{array}$ & \multirow{5}{*}{$\begin{array}{l}\text { Zhang et al., } 2013 \\
\text { Nguluma et al., } 2018\end{array}$} \\
\hline Boer & $\begin{array}{c}\text { nt1256 } \\
\text { g.197 } \\
\text { nt1388 } \\
\text { nt345 } \\
\text { nt298 } \\
\end{array}$ & $\begin{array}{l}\text { TTTA/- } \\
G>A \\
T>A \\
A>T \\
T>C \\
\end{array}$ & \\
\hline Haimen & nt1256 & TTTA/- & \\
\hline Motou & nt1256 & TTTA/- & \\
\hline Nubi & $n t 1256$ & TTTA/- & \\
\hline
\end{tabular}

1004

1005 
Table 4 Polymorphisms on Myostatin gene in horse.

\begin{tabular}{|c|c|c|c|}
\hline \multirow[t]{2}{*}{ Breed } & \multicolumn{2}{|c|}{$\begin{array}{l}\text { Polymorphisms } \\
\text { on MSTN }\end{array}$} & \multirow[t]{2}{*}{ Reference } \\
\hline & position & mutation & \\
\hline $\begin{array}{c}\text { American Quarter } \\
\text { Horse }\end{array}$ & g.66495326_66495327 & INS227 & Petersen et al., 2013 \\
\hline Andalusian & $\begin{array}{c}\text { g.26 } \\
\text { g.156 } \\
\text { g.1634 } \\
\text { g.2024 } \\
\text { g2115 } \\
\text { g.2327 } \\
\text { g.4230 }\end{array}$ & $\begin{array}{l}T>C \\
T>C \\
T>G \\
G>A \\
A>G \\
A>C \\
T>A\end{array}$ & Dall'Olio et al., 2010 \\
\hline Arabians horses & $\begin{array}{c}\text { g.2279 } \\
\text { g.66495696 } \\
\text { g.66495254 }\end{array}$ & $\begin{array}{l}\mathrm{A}>\mathrm{C} \\
\mathrm{T}>\mathrm{C} \\
\mathrm{C}>\mathrm{T}\end{array}$ & $\begin{array}{c}\text { Baron et al., } 2012 \\
\text { Stefaniuk et al., } 2016\end{array}$ \\
\hline Bardigiano & g.156 & $\mathrm{T}>\mathrm{C}$ & Dall'Olio et al., 2010 \\
\hline Haflinger & g.156 & $\mathrm{T}>\mathrm{C}$ & Dall'Olio et al., 2010 \\
\hline Hucul & $\begin{array}{c}\text { g.26 } \\
\text { g.66495696 } \\
\text { g.66493737 } \\
\text { g.66490010 } \\
\end{array}$ & $\begin{array}{l}T>C \\
T>C \\
T>C \\
T>C\end{array}$ & $\begin{array}{l}\text { Stefaniuk et al., } 2014 \\
\text { Stefaniuk et al., } 2016\end{array}$ \\
\hline Italian Saddle & $\begin{array}{l}\text { g.26 } \\
\text { g.156 }\end{array}$ & $\begin{array}{l}\mathrm{T}>\mathrm{C} \\
\mathrm{T}>\mathrm{C}\end{array}$ & Dall'Olio et al., 2010 \\
\hline Italian trotter & g.26 & $\mathrm{T}>\mathrm{C}$ & Dall'Olio et al., 2010 \\
\hline Polish Konik & $\begin{array}{l}\text { g.66495254 } \\
\text { g.66495696 } \\
\text { g.66493737 } \\
\text { g.66495254 } \\
\text { g.66490010 }\end{array}$ & $\begin{array}{l}\mathrm{C}>\mathrm{T} \\
\mathrm{T}>\mathrm{C} \\
\mathrm{T}>\mathrm{C} \\
\mathrm{C}>\mathrm{T} \\
\mathrm{T}>\mathrm{C}\end{array}$ & $\begin{array}{l}\text { Stefaniuk et al., } 2014 \\
\text { Stefaniuk et al., } 2016\end{array}$ \\
\hline Lipizzan & g.26 & $\mathrm{T}>\mathrm{C}$ & Dall'Olio et al., 2010 \\
\hline Maremmano & g.156 & $\mathrm{T}>\mathrm{C}$ & Dall'Olio et al., 2010 \\
\hline Murgese & g.156 & $\mathrm{T}>\mathrm{C}$ & Dall'Olio et al., 2010 \\
\hline Noric & $\begin{array}{l}\text { g.26 } \\
\text { g.156 }\end{array}$ & $\begin{array}{l}\mathrm{T}>\mathrm{C} \\
\mathrm{T}>\mathrm{C}\end{array}$ & Dall'Olio et al., 2010 \\
\hline Polish Heavy Draft & $\begin{array}{c}\text { g.26 } \\
\text { g.66495254 } \\
\text { g.66495696 } \\
\text { g.66493737 } \\
\text { g.66490010 }\end{array}$ & $\begin{array}{l}T>C \\
C>T \\
T>C \\
T>C \\
T>C\end{array}$ & $\begin{array}{l}\text { Stefaniuk et al., } 2014 \\
\text { Stefaniuk et al., } 2016\end{array}$ \\
\hline Rapid Heavy Draft & $\begin{array}{c}g .26 \\
g .156\end{array}$ & $\begin{array}{l}\mathrm{T}>\mathrm{C} \\
\mathrm{T}>\mathrm{C}\end{array}$ & Dall'Olio et al., 2010 \\
\hline Salernitano & g.156 & $\mathrm{T}>\mathrm{C}$ & Dall'Olio et al., 2010 \\
\hline Soraia & g.2478 & $\mathrm{G}>\mathrm{C}$ & Baron et al., 2012 \\
\hline $\begin{array}{c}\text { Thoroughbred } \\
\text { horse }\end{array}$ & $\begin{array}{l}\text { g.156 } \\
\text { g.1634 } \\
\text { g.2115 } \\
\text { g.2327 } \\
\end{array}$ & $\begin{array}{l}T>C \\
T>G \\
A>G \\
A>C\end{array}$ & $\begin{array}{l}\text { Dall'Olio et al., } 2010 \\
\text { Petersen et al., } 2013 \\
\text { Petersen et al., } 2013 \\
\text { Petersen et al., } 2013\end{array}$ \\
\hline
\end{tabular}




\begin{tabular}{|c|c|c|c|}
\hline Tolfetano & g.156 & T $>C$ & Dall'Olio et al., 2010 \\
\hline Uruguayan Creole & g.156 & T $>$ C & Dall'Olio et al., 2010 \\
\hline Ventasso & g.26 & T $>C$ & Dall'Olio et al., 2010 \\
\hline
\end{tabular}


1008 Table 5 Polymorphisms on Myostatin gene in pig.

\begin{tabular}{|c|c|c|c|}
\hline \multirow[t]{2}{*}{ Breed } & \multicolumn{2}{|c|}{$\begin{array}{c}\text { Polymorphisms } \\
\text { on MSTN }\end{array}$} & \multirow[t]{2}{*}{ Reference } \\
\hline & position & mutation & \\
\hline Belgian Pietrain & $\begin{array}{l}\text { g.435 } \\
\text { g.447 } \\
\text { g. } 879\end{array}$ & $\begin{array}{l}G>A \\
A>G \\
T>A\end{array}$ & Stinckens et al., 2008 \\
\hline Chinese Meishan & g.879 & $\mathrm{T}>\mathrm{A}$ & Qian et al., 2015 \\
\hline Yorkshire pig & $\begin{array}{c}\text { nt383 } \\
\text { exon 3 } \\
\text { (position no } \\
\text { specified) }\end{array}$ & $\begin{array}{l}T>A \\
G>A \\
C>T\end{array}$ & Jiang et al., 2002 \\
\hline
\end{tabular}

1009

1010 
1011 Table 6 Polymorphisms on Myostatin gene in rabbit.

\begin{tabular}{|c|c|c|c|}
\hline \multirow[t]{2}{*}{ Breed } & \multicolumn{2}{|c|}{$\begin{array}{c}\text { Polymorphisms } \\
\text { on MSTN }\end{array}$} & \multirow[t]{2}{*}{ Reference } \\
\hline & position & mutation & \\
\hline Belgian hare & $\begin{array}{c}\text { c. } 108 \\
\text { c. } 713 \\
\text { c. }{ }^{*} 194 \\
\text { c. } 747+34\end{array}$ & $\begin{array}{l}\mathrm{C}>\mathrm{T} \\
\mathrm{T}>\mathrm{A} \\
\mathrm{A}>\mathrm{G} \\
\mathrm{C}>\mathrm{T}\end{array}$ & Fontanesi et al., 2013 \\
\hline Burgundy fawn & $\begin{array}{c}\text { c. } 108 \\
\text { c. } 713 \\
\text { c. }{ }^{*} 194 \\
\text { c. } 747+34\end{array}$ & $\begin{array}{l}C>T \\
T>A \\
A>G \\
C>T\end{array}$ & Fontanesi et al., 2013 \\
\hline Checkered giant & $\begin{array}{c}\text { c. } 108 \\
\text { c. } 713 \\
\text { c. }{ }^{*} 194 \\
\text { c. } 747+34 \\
\end{array}$ & $\begin{array}{l}\mathrm{C}>\mathrm{T} \\
\mathrm{T}>\mathrm{A} \\
\mathrm{A}>\mathrm{G} \\
\mathrm{C}>\mathrm{T}\end{array}$ & Fontanesi et al., 2013 \\
\hline $\begin{array}{l}\text { Commercial } \\
\text { breeds (not } \\
\text { specified) }\end{array}$ & $\mathrm{nt} 476$ & $\mathrm{~T}>\mathrm{C}$ & Qiao et al., 2014 \\
\hline Giant grey & $\begin{array}{c}\text { c. } 108 \\
\text { c. } 713 \\
\text { c. }{ }^{*} 194 \\
\text { c. } 747+34\end{array}$ & $\begin{array}{l}\mathrm{C}>\mathrm{T} \\
\mathrm{T}>\mathrm{A} \\
\mathrm{A}>\mathrm{G} \\
\mathrm{C}>\mathrm{T}\end{array}$ & Fontanesi et al., 2013 \\
\hline Giant Grey & $\begin{array}{c}\text { c. }-125 \\
\text { c. } 373+234\end{array}$ & $\begin{array}{l}\mathrm{T}>\mathrm{C} \\
\mathrm{T}>\mathrm{C}\end{array}$ & Sternstein et al., 2014 \\
\hline $\begin{array}{c}\text { New Zealand } \\
\text { White }\end{array}$ & $\begin{array}{c}\text { c. }-125 \\
\text { c. } 373+234\end{array}$ & $\begin{array}{l}\mathrm{T}>\mathrm{C} \\
\mathrm{T}>\mathrm{C}\end{array}$ & Sternstein et al., 2014 \\
\hline
\end{tabular}

1012

1013 
1014 Table 7 Polymorphisms on Myostatin gene in poultry.

\begin{tabular}{|c|c|c|c|}
\hline \multirow[t]{2}{*}{ Breed } & \multicolumn{2}{|c|}{$\begin{array}{c}\text { Polymorphisms } \\
\text { on MSTN }\end{array}$} & \multirow[t]{2}{*}{ Reference } \\
\hline & position & mutation & \\
\hline Arbor Acre & $\begin{array}{c}\mathrm{nt} 167 \\
\mathrm{nt177} \\
\mathrm{nt} 304 \\
\mathrm{nt} 322 \\
\mathrm{nt} 326 \\
\mathrm{nt} 334 \\
\mathrm{nt} 334 \\
\mathrm{nt1346} \\
\mathrm{nt1375} \\
\mathrm{nt6935} \\
\mathrm{nt} 7263 \\
\end{array}$ & $\begin{array}{l}G>A \\
T>C \\
G>A \\
A>G \\
A>G \\
C>T \\
C>G \\
C>T \\
G>A \\
A>G \\
A>T\end{array}$ & $\begin{array}{c}\text { Gu et al., } 2003 \\
\text { Zhang et al., } 2012\end{array}$ \\
\hline Bian chicken & nt234 & $\mathrm{G}>\mathrm{A}$ & Zhang et al., 2012 \\
\hline Gaoyou ducks & $\mathrm{nt2701}$ & $\mathrm{G}>\mathrm{A}$ & Liu et al., 2012 \\
\hline Jinghai & $\begin{array}{c}\mathrm{nt326} \\
\mathrm{nt334} \\
\mathrm{nt1346} \\
\mathrm{nt1375} \\
\end{array}$ & $\begin{array}{l}A>G \\
C>G \\
C>T \\
G>A\end{array}$ & Zhang et al., 2012 \\
\hline Pekin duck & $\begin{array}{l}\text { nt129 } \\
\text { nt708 } \\
\text { nt952 }\end{array}$ & $\begin{array}{l}\mathrm{T}>\mathrm{C} \\
\mathrm{T}>\mathrm{C} \\
\mathrm{T}>\mathrm{C}\end{array}$ & Xu et al., 2013 \\
\hline Sansui duck & $\begin{array}{c}\text { g. } 106 \\
\text { g.120 } \\
\text { g.159 } \\
\text { g.5368 } \\
\text { g.5389 } \\
\text { g.5410 }\end{array}$ & $\begin{array}{l}G>A \\
A>G \\
G>A \\
G>A \\
A>C \\
G>A\end{array}$ & Zhao et al., 2016 \\
\hline Youxi & $\begin{array}{c}\text { nt326 } \\
\text { nt334 } \\
\text { nt1346 } \\
\text { nt1375 } \\
\end{array}$ & $\begin{array}{l}A>G \\
C>G \\
C>T \\
G>A\end{array}$ & Zhang et al., 2012 \\
\hline
\end{tabular}

1015

1016 